\title{
Estimating the burden of SARS-CoV-2 in France
}

\author{
Henrik Salje ${ }^{1,2,3 *}$, Cécile Tran Kiem ${ }^{1,4 *}$, Noémie Lefrancq ${ }^{1}$, Noémie Courtejoie ${ }^{5}$, Paolo Bosetti1, Juliette Paireau ${ }^{1,6}$, \\ Alessio Andronico', Nathanaël Hozé ${ }^{1}$, Jehanne Richet ${ }^{5}$, Claire-Lise Dubost ${ }^{5}$, Yann Le Strat ${ }^{6}$, Justin Lessler ${ }^{3}$, \\ Daniel Levy-Bruhl $^{6}$, Arnaud Fontanet ${ }^{7,8}$, Lulla Opatowski ${ }^{9,10}$, Pierre-Yves Boelle ${ }^{11}$, Simon Cauchemez ${ }^{1 \dagger}$ \\ ${ }^{1}$ Mathematical Modelling of Infectious Diseases Unit, Institut Pasteur, UMR2000, CNRS, Paris, France. 2Department of Genetics, University of Cambridge, Cambridge, UK. \\ ${ }^{3}$ Department of Epidemiology, Johns Hopkins Bloomberg School of Public Health, Baltimore, MD, USA. ${ }^{4}$ Collège Doctoral, Sorbonne Université, Paris, France. ${ }^{5}$ DREES, \\ Ministère des Solidarités et de la Santé, Paris, France. ${ }^{6}$ Santé Publique France, French National Public Health Agency, Saint-Maurice, France. ${ }^{7}$ Emerging Diseases \\ Epidemiology Unit, Institut Pasteur, Paris, France. ${ }^{8}$ PACRI Unit, Conservatoire National des Arts et Métiers, Paris, France. ${ }^{9}$ Epidemiology and Modelling of Antibiotic Evasion \\ Unit, Institut Pasteur, Paris, France. ${ }^{10}$ Anti-infective Evasion and Pharmacoepidemiology Team, CESP, Université Paris-Saclay, UVSQ, INSERM U1018, Montigny-le- \\ Bretonneux, France. ${ }^{11}$ Institut Pierre Louis d'Epidémiologie et de Santé Publique, Sorbonne Université, INSERM, Paris, France. \\ *These authors contributed equally to this work.
}

†Corresponding author. Email: simon.cauchemez@pasteur.fr

France has been heavily affected by the SARS-CoV-2 epidemic and went into lockdown on the 17 March 2020. Using models applied to hospital and death data, we estimate the impact of the lockdown and current population immunity. We find $3.6 \%$ of infected individuals are hospitalized and $0.7 \%$ die, ranging from $0.001 \%$ in those $<20$ years of age (ya) to $10.1 \%$ in those $>80 y$ a. Across all ages, men are more likely to be hospitalized, enter intensive care, and die than women. The lockdown reduced the reproductive number from 2.90 to 0.67 (77\% reduction). By 11 May 2020, when interventions are scheduled to be eased, we project 2.8 million (range: 1.8-4.7) people, or 4.4\% (range: $2.8-7.2$ ) of the population, will have been infected. Population immunity appears insufficient to avoid a second wave if all control measures are released at the end of the lockdown.

The worldwide pandemic of SARS-CoV-2, the coronavirus which causes COVID-19, has resulted in unprecedented responses, with many affected nations confining residents to their homes. Much like the rest of Europe, France has been hit hard by the epidemic and went into lockdown on the 17 March 2020. It was hoped that this would result in a sharp decline in ongoing spread, as was observed when China locked down following the initial emergence of the virus ( 1 , 2). Following the expected reduction in cases, the French government has announced it will ease restrictions on the 11 May 2020. To exit from the lockdown without escalating infections, we need to understand the underlying level of population immunity and infection, identify those most at risk for severe disease and the impact of current control efforts.

Daily reported numbers of hospitalizations and deaths only provide limited insight into the state of the epidemic. Many people will either develop no symptoms or symptoms so mild they will not be detected through healthcare-based surveillance. The concentration of hospitalized cases in older individuals has led to hypotheses that there may be widespread "silent" transmission in younger individuals (3). If the majority of the population is infected, viral transmission would slow, potentially reducing the need for the stringent intervention measures currently employed.
We present a suite of modeling analyses to characterize the dynamics of SARS-CoV-2 transmission in France and the impact of the lockdown on these dynamics. We elucidate the risk of SARS-CoV-2 infection and severe outcomes by age and sex and estimate the current proportion of the national and regional populations that have been infected and might be at least temporarily immune (4). These models support healthcare planning of the French government by capturing hospital bed capacity requirements.

As of 7 May 2020, there were 95,210 incident hospitalizations due to SARS-CoV-2 reported in France and 16,386 deaths in hospitals, with the east of the country and the capital, Paris, particularly affected (Fig. 1, A and B). The mean age of hospitalized patients was 68ya and the mean age of the deceased was $79 y$ y with $50.0 \%$ of hospitalizations occurring in individuals $>70 y a$ and $81.6 \%$ of deaths within that age bracket; $56.2 \%$ of hospitalizations and $60.3 \%$ of deaths were male (Fig. 1, C to E). To reconstruct the dynamics of all infections, including mild ones, we jointly analyze French hospital data with the results of a detailed outbreak investigation aboard the Diamond Princess cruise ship where all passengers were subsequently tested (719 infections, 14 deaths currently). By coupling the passive surveillance data from French hospitals with the active surveillance performed 
aboard the Diamond Princess, we disentangle the risk of being hospitalized in those infected from the underlying probability of infection $(5,6)$.

We find that $3.6 \%$ of infected individuals are hospitalized (95\% CrI: $2.1-5.6)$, ranging from $0.2 \%$ (95\% CrI: $0.1-0.2)$ in females under <20ya to $45.9 \%$ (95\% CrI: $27.2-70.9)$ in males $>80$ ya (Fig. 2A and table S1). Once hospitalized, on average 19.0\% (95\% CrI: 18.7-19.4\%) patients enter ICU after a mean delay of 1.5 days (fig. S1). We observe an increasing probability of entering ICU with age-however, this drops for those $>70$ ya (Fig. 2B and table S2). Overall, 18.1\% (95\% CrI: 17.818.4) of hospitalized individuals go on to die (Fig. 2C). The overall probability of death among those infected (the Infection Fatality Ratio, IFR) is $0.7 \%$ (95\% CrI: 0.4-1.0), ranging from $0.001 \%$ in those under $20 y a$ to $10.1 \%$ (95\% CrI: $6.0-15.6$ ) in those $>80 y a$ (Fig. 2D and table S2). Our estimate of overall IFR is similar to other recent studies that found values of between 0.5 and $0.7 \%$ for the Chinese epidemic (6-8). We find men have a consistently higher risk than women of hospitalization (RR 1.25, 95\% CrI: 1.22-1.29), ICU admission once hospitalized (RR: 1.61, 95\% CrI: 1.56-1.67) and death following hospitalization (RR: 1.47, 95\% CrI: 1.42-1.53) (fig. S2).

We identify two clear subpopulations in those cases that are hospitalized: individuals that die quickly upon hospital admission ( $15 \%$ of fatal cases, mean time to death of 0.67 days) and individuals who die after longer time periods (85\% of fatal cases, mean time to death of 13.2 days) (fig. S3). The proportion of fatal cases who die rapidly remains approximately constant across age-groups (fig. S4 and table S3). Potential explanations for different subgroups of fatal cases include heterogeneous patterns of healthcare seeking, access to care, underlying comorbidities, such as metabolic disease and other inflammatory conditions. A role for immunopathogenesis has also been proposed (9-12).

We next fit national and regional transmission models to ICU admission, hospital admission, and bed occupancy (both ICU and general wards) (Fig. 3, A to D, fig. S5, and tables S4 to S6), allowing for reduced age-specific daily contact patterns following the lockdown and changing patterns of ICU admission over time (fig. S17). We find that the basic reproductive number $\mathrm{R}_{0}$ prior to the implementation of the lockdown was 2.90 (95\% CrI: 2.80-2.99). The lockdown resulted in a $77 \%$ (95\% CI: 76-78) reduction in transmission, with the reproduction number $\mathrm{R}$ dropping to 0.67 (95\% CrI: 0.650.68 ). We forecast that by the 11 May 2020, 2.8 million (range: 1.8-4.7, when accounting for uncertainty in the probability of hospitalization given infection) people will have been infected, representing 4.4\% (range: 2.8-7.2) of the French population (Fig. 3E). This proportion will be 9.9\% (range: 6.615.7) in Ile-de-France, which includes Paris, and 9.1\% (range: 6.0-14.6) in Grand Est, the two most affected regions of the country (Fig. 3F and fig. S5). Assuming a basic reproductive number of $\mathrm{R}_{0}=3.0$, it would require around $65 \%$ of the population to be immune for the epidemic to be controlled by immunity alone. Our results therefore strongly suggest that, without a vaccine, herd immunity on its own will be insufficient to avoid a second wave at the end of the lockdown. Efficient control measures need to be maintained beyond the 11 May.

Our model can help inform the ongoing and future response to COVID-19. National ICU daily admissions have gone from 700 at the end of March to 66 on 7 May. Hospital admissions have declined from 3600 to 357 over the same time period, with consistent declines observed throughout France (fig. S5). By 11 May we project 3900 (range: 26006300 ) daily infections across the country, down from between $150,000-390,000$ immediately prior to the lockdown. At a regional level, we estimate that $58 \%$ of infections will be in Ilede-France and Grand Est combined. We find that the time people spend in ICU appears to differ across the country, which may be due to differences in health care practices (table S5).

Using our modeling framework, we are able to reproduce the observed number of hospitalizations by age and sex in France and the number of observed deaths aboard the Diamond Princess (fig. S6). As a validation, our approach is also able to correctly identify parameters in simulated datasets where the true values are known (fig. S7). As cruise ship passengers may represent a different, healthier population than average French citizens, we run a sensitivity analysis where Diamond Princess passengers are 25\% less likely to die than French citizens (Fig. 4 and fig. S8). We also run sensitivity analyses with longer delays between symptom onset and hospital admission, missed infections aboard the Diamond Princess, equal attack rates across all ages, reduced infectivity in younger individuals, a contact matrix with unchanged structure before/during the lockdown and one with very high isolation of elderly individuals during the lockdown. These different scenarios result in mean IFRs from 0.5 to $0.9 \%$, the proportion of the population infected by the 11 May 2020 ranging from $1.7-8.9 \%$, the number of daily infections at this date ranging from 1700 to 9600 and a range of reproductive numbers post lockdown of 0.62-0.73 (Fig. 4, figs. S8 to S15, and tables S7 to S12).

A seroprevalence of $3 \%$ (range: $0-3 \%$ ) has been estimated among blood donors in Hauts-de-France, which is consistent with our model predictions (range: 1-3\%) for this population if we account for a 10-day delay for seroconversion $(13,14)$. Future additional serological data will help further refine estimates of the proportion of the population infected.

While we focus on deaths occurring in hospitals, there are also non-hospitalized COVID-19 deaths, including $>9000$ in retirement homes in France (15). We explicitly removed retirement home population from our analyses as transmission 
dynamics may be different in these closed populations. This means our estimates of immunity in the general population are unaffected by deaths in retirement homes, however, in the event of large numbers of non-hospitalized deaths in the wider community, we would underestimate the proportion of the population infected. Analyses of excess death will be important to explore these issues.

This study shows the massive impact the French lockdown had on SARS-CoV-2 transmission. Our modeling approach has allowed us to estimate underlying probabilities of infection, hospitalization and death, which is essential for the interpretation of COVID-19 surveillance data. The forecasts we provide can inform lockdown exit strategies. Our estimates of a low level of immunity against SARS-CoV-2 indicates that efficient control measures that limit transmission risk will have to be maintained beyond the 11 May 2020 to avoid a rebound of the epidemic.

\section{REFERENCES AND NOTES}

1. M. U. G. Kraemer, C.-H. Yang, B. Gutierrez, C.-H. Wu, B. Klein, D. M. Pigott, L. du Plessis, N. R. Faria, R. Li, W. P. Hanage, J. S. Brownstein, M. Layan, A. Vespignani, H. Tian, C. Dye, O. G. Pybus, S. V. Scarpino; Open COVID-19 Data Working Group, The effect of human mobility and control measures on the COVID-19 epidemic in China. Science 368, 493-497 (2020). doi:10.1126/science.abb4218 Medline

2. H. Tian, Y. Liu, Y. Li, C.-H. Wu, B. Chen, M. U. G. Kraemer, B. Li, J. Cai, B. Xu, Q. Yang, B. Wang, P. Yang, Y. Cui, Y. Song, P. Zheng, Q. Wang, O. N. Bjornstad, R. Yang, B. T. Grenfell, O. G. Pybus, C. Dye, An investigation of transmission control measures during the first 50 days of the COVID-19 epidemic in China. Science 368, 638-642 (2020). doi:10.1126/science.abb6105 Medline

3. J. Lourenço, R. Paton, M. Ghafari, M. Kraemer, C. Thompson, P. Simmonds, P. Klenerman, S. Gupta, Fundamental principles of epidemic spread highlight the immediate need for large-scale serological surveys to assess the stage of the SARS-CoV-2 epidemic. medRxiv 2020.03.24.20042291 [Preprint]. 26 March 2020. https://doi.org/10.1101/2020.03.24.20042291.

4. L. Bao, W. Deng, H. Gao, C. Xiao, J. Liu, J. Xue, Q. Lv, J. Liu, P. Yu, Y. Xu, F. Qi, Y. Qu, F. Li, Z. Xiang, H. Yu, S. Gong, M. Liu, G. Wang, S. Wang, Z. Song, W. Zhao, Y. Han, L. Zhao, X. Liu, Q. Wei, C. Qin, Reinfection could not occur in SARS-CoV-2 infected rhesus macaques. bioRxiv 2020.03.13.990226 [Preprint]. 14 March 2020. https://doi.org/10.1101/2020.03.13.990226.

5. J. Lessler, H. Salje, M. D. Van Kerkhove, N. M. Ferguson, S. Cauchemez, I. Rodriquez-Barraquer, R. Hakeem, T. Jombart, R. Aguas, A. Al-Barrak, D. A. T. Cummings; MERS-CoV Scenario and Modeling Working Group, Estimating the severity and subclinical burden of Middle East respiratory syndrome coronavirus infection in the Kingdom of Saudi Arabia. Am. J. Epidemiol. 183, 657-663 (2016). doi:10.1093/aje/kwv452 Medline

6. R. Verity, L. C. Okell, I. Dorigatti, P. Winskill, C. Whittaker, N. Imai, G. CuomoDannenburg, H. Thompson, P. G. T. Walker, H. Fu, A. Dighe, J. T. Griffin, M. Baguelin, S. Bhatia, A. Boonyasiri, A. Cori, Z. Cucunubá, R. FitzJohn, K. Gaythorpe, W. Green, A. Hamlet, W. Hinsley, D. Laydon, G. Nedjati-Gilani, S. Riley, S. van Elsland, E. Volz, H. Wang, Y. Wang, X. Xi, C. A. Donnelly, A. C. Ghani, N. M. Ferguson, Estimates of the severity of coronavirus disease 2019: A modelbased analysis. Lancet Infect. Dis. 10.1016/S1473-3099(20)30243-7 (2020). doi:10.1016/S1473-3099(20)30243-7 Medline

7. T. W. Russell, J. Hellewell, C. I. Jarvis, K. van Zandvoort, S. Abbott, R. Ratnayake, S. Flasche, R. M. Eggo, W. J. Edmunds, A. J. Kucharski; Cmmid Covid-Working Group, Estimating the infection and case fatality ratio for coronavirus disease
(COVID-19) using age-adjusted data from the outbreak on the Diamond Princess cruise ship, February 2020. Euro Surveill. 25, 2000256 (2020). doi:10.2807/1560-7917.ES.2020.25.12.2000256 Medline

8. K. Mizumoto, K. Kagaya, G. Chowell, Early epidemiological assessment of the transmission potential and virulence of coronavirus disease 2019 (COVID-19) in Wuhan City: China, January-February, 2020. medRxiv 2020.02.12.20022434 [Preprint]. 13 March 2020. https://doi.org/10.1101/2020.02.12.20022434.

9. L. Peeples, News Feature: Avoiding pitfalls in the pursuit of a COVID-19 vaccine. Proc. Natl. Acad. Sci. U.S.A. 117, 8218-8221 (2020). doi:10.1073/pnas.2005456117 Medline

10. D. Ricke, R. W. Malone, Medical Countermeasures Analysis of 2019-nCoV and Vaccine Risks for Antibody-Dependent Enhancement (ADE), 27 February 2020; https://ssrn.com/abstract $=3546070$.

11. J. Yang, Y. Zheng, X. Gou, K. Pu, Z. Chen, Q. Guo, R. Ji, H. Wang, Y. Wang, Y. Zhou, Prevalence of comorbidities and its effects in patients infected with SARS-CoV-2 A systematic review and meta-analysis. Int. J. Infect. Dis. 94, 91-95 (2020). doi:10.1016/ji.jid.2020.03.017 Medline

12. M. Bolles, D. Deming, K. Long, S. Agnihothram, A. Whitmore, M. Ferris, W. Funkhouser, L. Gralinski, A. Totura, M. Heise, R. S. Baric, A double-inactivated severe acute respiratory syndrome coronavirus vaccine provides incomplete protection in mice and induces increased eosinophilic proinflammatory pulmonary response upon challenge. J. Virol. 85, 12201-12215 (2011). doi:10.1128/JVl.06048-11 Medline

13. A. Fontanet, L. Tondeur, Y. Madec, R. Grant, C. Besombes, N. Jolly, S. F. Pellerin M.-N. Ungeheuer, I. Cailleau, L. Kuhmel, S. Temmam, C. Huon, K.-Y. Chen, B. Crescenzo, S. Munier, C. Demeret, L. Grzelak, I. Staropoli, T. Bruel, P. Gallian, S. Cauchemez, S. van der Werf, O. Schwartz, M. Eloit, B. Hoen, Cluster of COVID-19 in northern France: A retrospective closed cohort study. medRxiv 2020.04.18.20071134 [Preprint]. 23 April 2020. https://doi.org/10.1101/2020.04.18.20071134.

14. L. Grzelak, S. Temmam, C. Planchais, C. Demeret, C. Huon, F. Guivel, I. Staropoli, M. Chazal, J. Dufloo, D. Planas, J. Buchrieser, M. M. Rajah, R. Robinot, F. Porrot, M. Albert, K.-Y. Chen, B. Crescenzo, F. Donati, F. Anna, P. Souque, M. Gransagne, J. Bellalou, M. Nowakowski, M. Backovic, L. Bouadma, L. Le Fevre, Q. Le Hingrat, D. Descamps, A. Pourbaix, Y. Yazdanpanah, L. Tondeur, C. Besombes, M.-N. Ungeheuer, G. Mellon, P. Morel, S. Rolland, F. Rey, S. Behillil, V. Enouf, A. Lemaitre, M.-A. Creach, S. Petres, N. Escriou, P. Charneau, A. Fontanet, B. Hoen, T. Bruel, M. Eloit, H. Mouquet, O. Schwartz, S. van der Werf, SARS-CoV-2 serological analysis of COVID-19 hospitalized patients, pauci-symptomatic individuals and blood donors. medRxiv 2020.04.21.20068858 [Preprint]. 24 April 2020. https://doi.org/10.1101/2020.04.21.20068858.

15. French Government website, Info Coronavirus Covid 19 (in French); www.gouvernement.fr/info-coronavirus/carte-et-donnees.

16. H. Salje, C. Tran Kiem, Code and data for: Estimating the burden of SARS-CoV-2 in France, Version 1.0, Zenodo (2020); http://doi.org/10.5281/zenodo.3813815.

17. Field Briefing: Diamond Princess COVID-19 Cases, 20 Feb Update (2020); www.niid.go.jp/niid/en/2019-ncov-e/9417-covid-dp-fe-02.html.

18. Ministry of Health, Labour and Welfare, About new coronavirus infection (in Japanese); www.mhlw.go.jp/stf/seisakunitsuite/bunya/0000164708_00001.html.

19. H. Nishiura, D. Klinkenberg, M. Roberts, J. A. P. Heesterbeek, Early epidemiological assessment of the virulence of emerging infectious diseases: A case study of an influenza pandemic. PLOS ONE 4, e6852 (2009). doi:10.1371/journal.pone.0006852 Medline

20. G. Béraud, S. Kazmercziak, P. Beutels, D. Levy-Bruhl, X. Lenne, N. Mielcarek, Y. Yazdanpanah, P.-Y. Boëlle, N. Hens, B. Dervaux, The French connection: The first large population-based contact survey in France relevant for the spread of 
infectious diseases. PLOS ONE 10, e0133203 (2015). doi:10.1371/journal.pone.0133203 Medline

21. K. Mizumoto, K. Kagaya, A. Zarebski, G. Chowell, Estimating the asymptomatic proportion of coronavirus disease 2019 (COVID-19) cases on board the Diamond Princess cruise ship, Yokohama, Japan, 2020. Euro Surveill. 25, (2020). doi:10.2807/1560-7917.ES.2020.25.10.2000180 Medline

22. Stan Development Team, RStan: the R interface to Stan (2020); https://mcstan.org/.

23. Z. Du, X. Xu, Y. Wu, L. Wang, B. J. Cowling, L. A. Meyers, Serial interval of COVID19 among publicly reported confirmed cases. Emerg. Infect. Dis. 10.3201/eid2606.200357 (2020). doi:10.3201/eid2606.200357 Medline

24. Q. Bi, Y. Wu, S. Mei, C. Ye, X. Zou, Z. Zhang, X. Liu, L. Wei, S. A. Truelove, T. Zhang, W. Gao, C. Cheng, X. Tang, X. Wu, Y. Wu, B. Sun, S. Huang, Y. Sun, J. Zhang, T. Ma, J. Lessler, T. Feng, Epidemiology and Transmission of COVID-19 in Shenzhen China: Analysis of 391 cases and 1,286 of their close contacts. medRxiv 2020.03.03.20028423 [Preprint]. 4 March 2020. https://doi.org/10.1101/2020.03.03.20028423.

25. L. Tindale, M. Coombe, J. E. Stockdale, E. Garlock, W. Y. V. Lau, M. Saraswat, Y.H. B. Lee, L. Zhang, D. Chen, J. Wallinga, C. Colijn, Transmission interval estimates suggest pre-symptomatic spread of COVID-19. medRxiv 2020.03.03.20029983 [Preprint]. 6 March 2020. https://doi.org/10.1101/2020.03.03.20029983.

26. S. Funk, socialmixr; https://github.com/sbfnk/socialmixr.

27. O. Diekmann, J. A. Heesterbeek, J. A. Metz, On the definition and the computation of the basic reproduction ratio $R_{0}$ in models for infectious diseases in heterogeneous populations. J. Math. Biol. 28, 365-382 (1990). doi:10.1007/BF00178324 Medline

28. N. Hens, G. M. Ayele, N. Goeyvaerts, M. Aerts, J. Mossong, J. W. Edmunds, P. Beutels, Estimating the impact of school closure on social mixing behaviour and the transmission of close contact infections in eight European countries. BMC Infect. Dis. 9, 187 (2009). doi:10.1186/1471-2334-9-187 Medline

29. Décret $n^{\circ} 2020-260$ du 16 mars 2020 portant réglementation des déplacements dans le cadre de la lutte contre la propagation du virus covid-19, Legifrance; www.legifrance.gouv.fr/affichTexte.do?cidTexte=JORFTEXT000041728476\&ca tegorieLien=id.

30. A. Gelman, J. B. Carlin, H. S. Stern, D. B. Rubin, Bayesian Data Analysis (CRC Texts in Statistical Science, Chapman and Hall, ed. 2, 2004).

31. COVID-19 Community Mobility Report, www.google.com/covid19/mobility/.

32. J. Wallinga, M. Lipsitch, How generation intervals shape the relationship between growth rates and reproductive numbers. Proc. Biol. Sci. 274, 599-604 (2007). doi:10.1098/rspb.2006.3754 Medline

\section{ACKNOWLEDGMENTS}

Funding: We acknowledge financial support from the Investissement d'Avenir program, the Laboratoire d'Excellence Integrative Biology of Emerging Infectious Diseases program (Grant ANR-10-LABX-62-IBEID), Santé Publique France, the INCEPTION project (PIA/ANR-16-CONV-0005) and the European Union's Horizon 2020 research and innovation program under grant agreement No 101003589. HS acknowledges support from the European Research Council (No. 804744) and University of Cambridge COVID-19 Rapid Response Grant. Author contributions: H.S., C.T.K. and S.C. conceived the study, developed the methods, performed analyses and co-wrote the paper. N.L., N.C., N.H., A.A., P.B., J.P., J.R., C.-L.D., L.O., P.Y.B., A.F., J.L., D.L.B., Y.L.S. contributed to data collection and analysis. All authors contributed to paper revisions. Competing interests: The authors declare no competing interests. Data and materials availability: Code for the paper is available at (16). This work is licensed under a Creative Commons Attribution 4.0 International (CC BY 4.0) license, which permits unrestricted use, distribution, and reproduction in any medium, provided the original work is properly cited. To view a copy of this license, visit https://creativecommons.org/licenses/by/4.0/. This license does not apply to figures/photos/artwork or other content included in the article that is credited to a third party; obtain authorization from the rights holder before using such material.

\section{SUPPLEMENTARY MATERIALS}

science.sciencemag.org/cgi/content/full/science.abc3517/DC1

Materials and Methods

Supplementary Text

Figs. S1 to S17

Tables S1 to S12

References (17-32)

MDAR Reproducibility Checklist

20 April 2020; accepted 11 May 2020

Published online 13 May 2020

10.1126/science.abc3517 

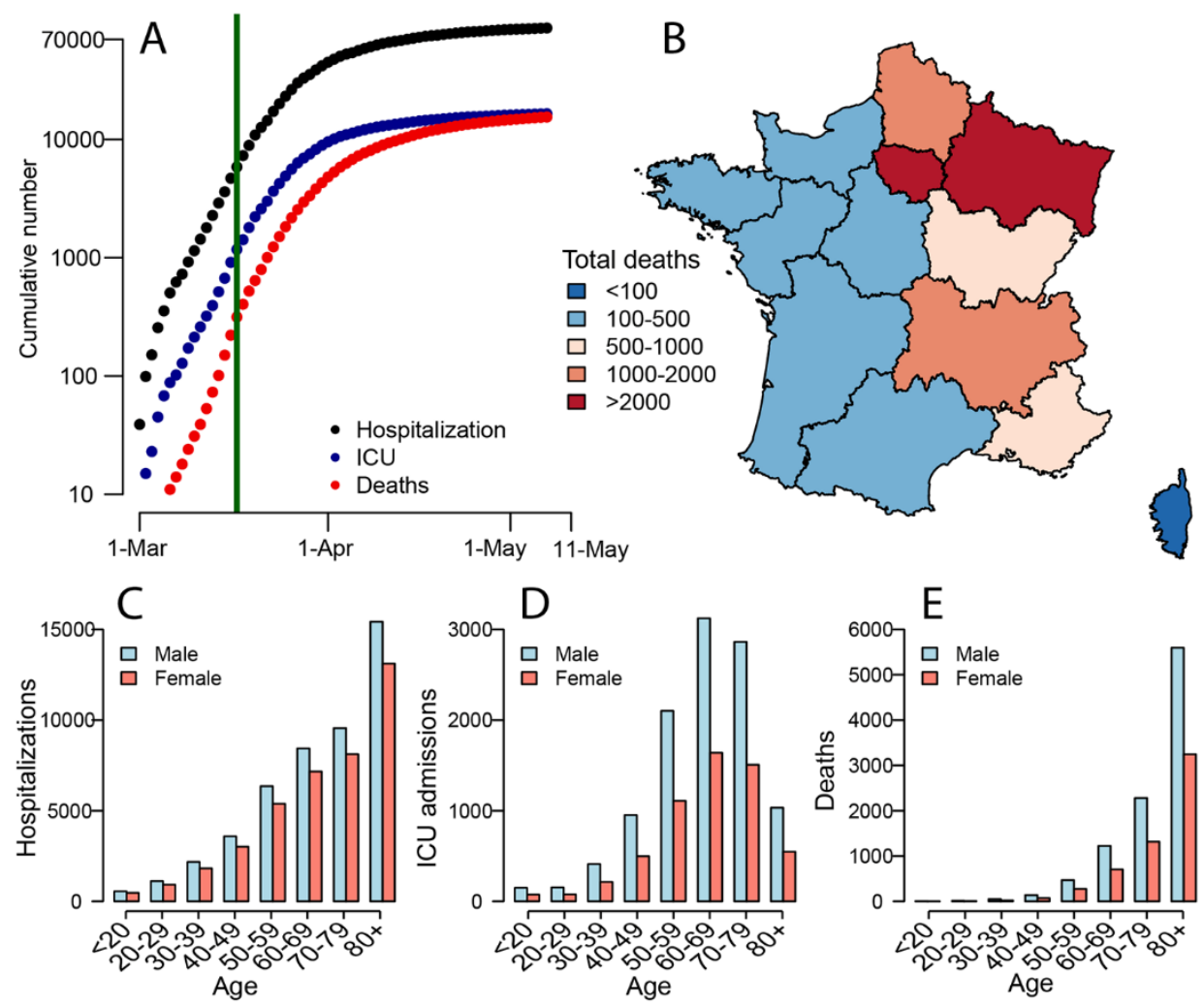

Fig. 1. COVID-19 hospitalizations and deaths in France. (A) Cumulative number of general ward and ICU hospitalizations, ICU admissions and deaths from SARS-CoV-2 in France. The green line indicates the time when the lockdown was put in place in France. (B) Distribution of deaths in France. Number of (C) hospitalizations, (D) ICU and (E) deaths by age group and sex in France. 

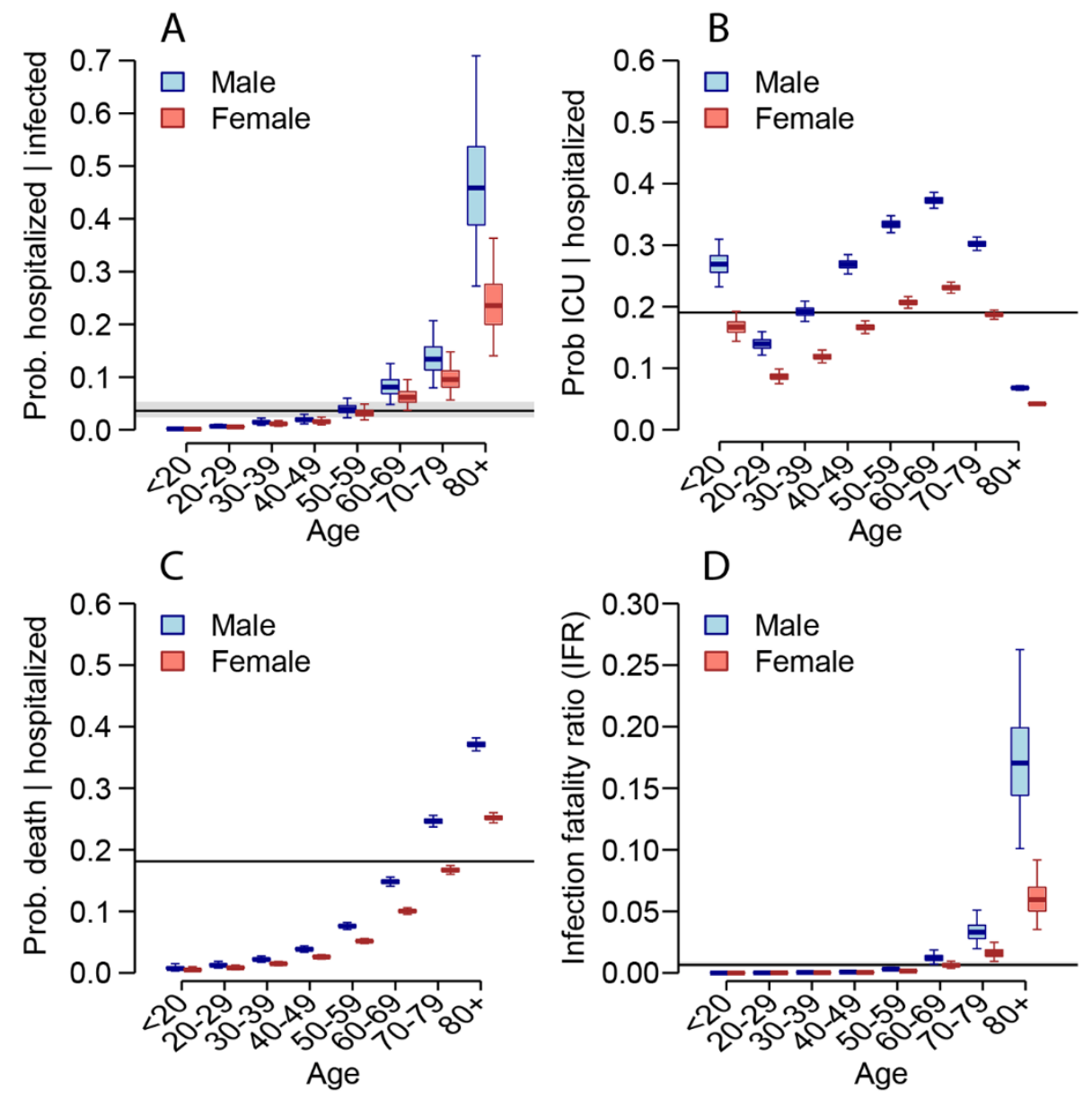

Fig. 2. Probabilities of hospitalization, ICU admittance and death. (A) Probability of hospitalization among those infected as a function of age and sex. (B) Probability of ICU admission among those hospitalized as a function of age and sex. (C) Probability of death among those hospitalized as a function of age and sex. (D) Probability of death among those infected as a function of age and sex. For each panel, the black line and grey shaded region represents the overall mean across all ages. The boxplots represent the 2.5, 25, 50, 75 and 97.5 percentiles of the posterior distributions. 

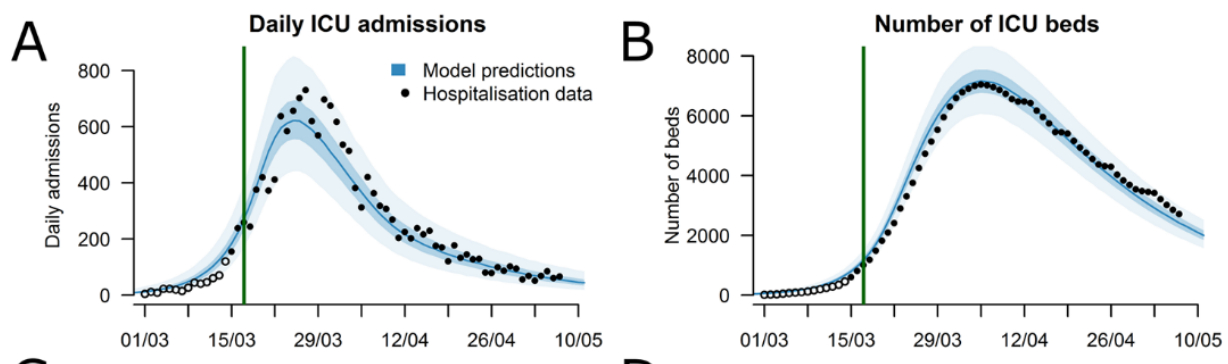

C

D
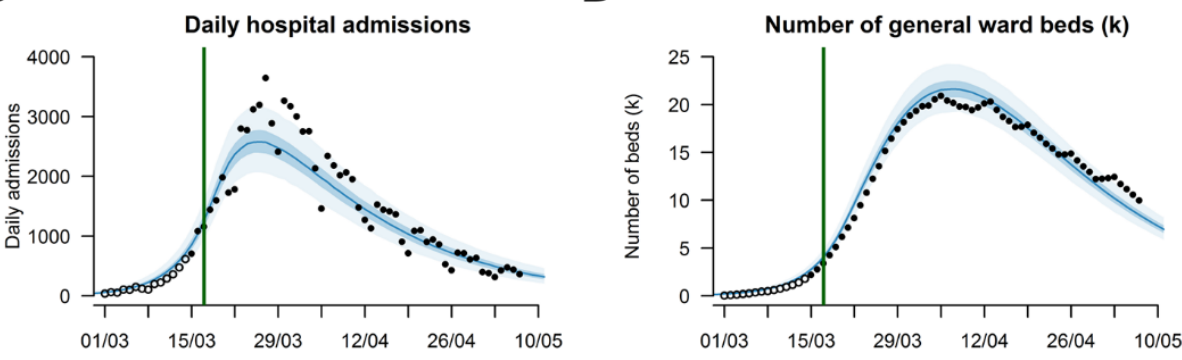

E

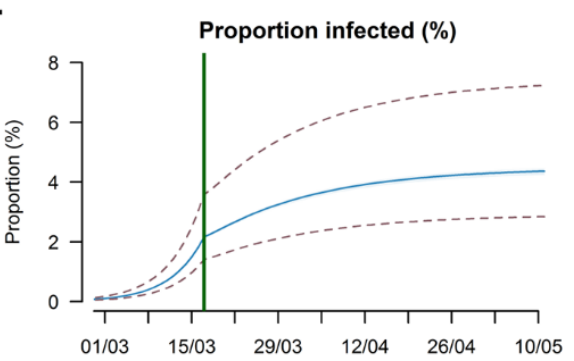

$\mathrm{F}$

Proportion infected - May 11th (\%)

\section{G}
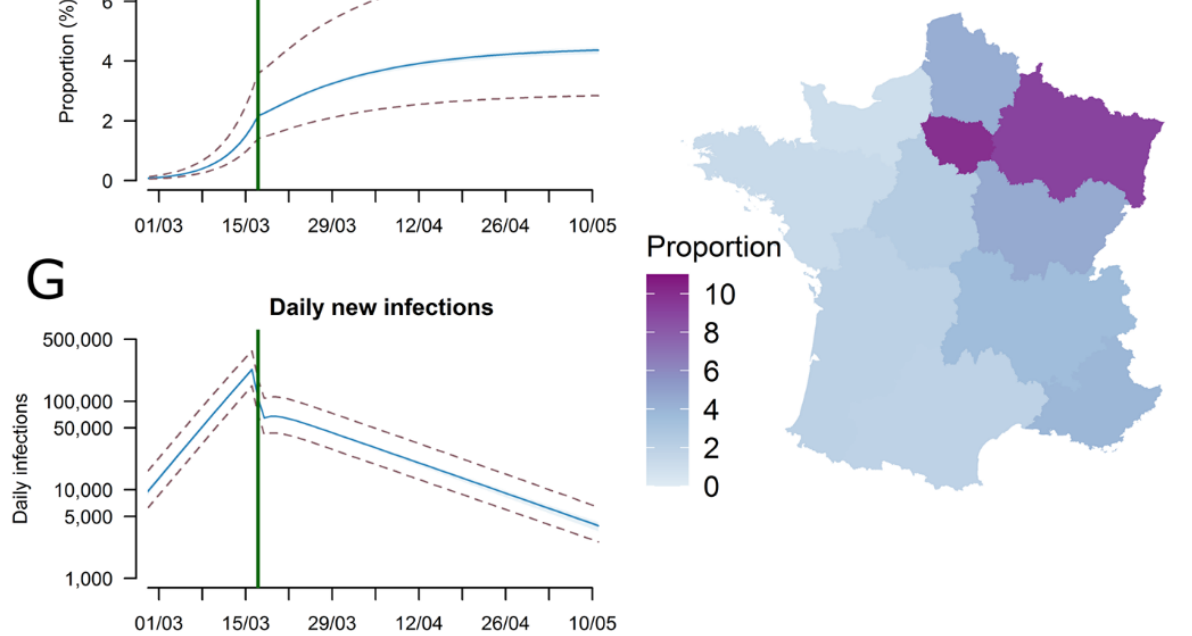

Fig. 3. Time course of the SARS-CoV-2 epidemic to 11 May 2020. (A) Daily admissions in ICU in metropolitan France. (B) Number of ICU beds occupied in metropolitan France. (C) Daily hospital admissions in metropolitan France. (D) Number of general ward beds occupied in metropolitan France (E) Daily new infections in metropolitan France (logarithmic scale). (F) Predicted proportion of the population infected by 11 May 2020 for each of the 13 regions in metropolitan France. (G) Predicted proportion of the population infected in metropolitan France. The black circles in panels (A), (B), (C) and (D) represent hospitalization data used for the calibration and the open circles hospitalization data that were not used for calibration. The dotted lines in panels $(E)$ and $(G)$ represent the 95\% uncertainty range stemming from the uncertainty in the probability of hospitalization following infection. 
A

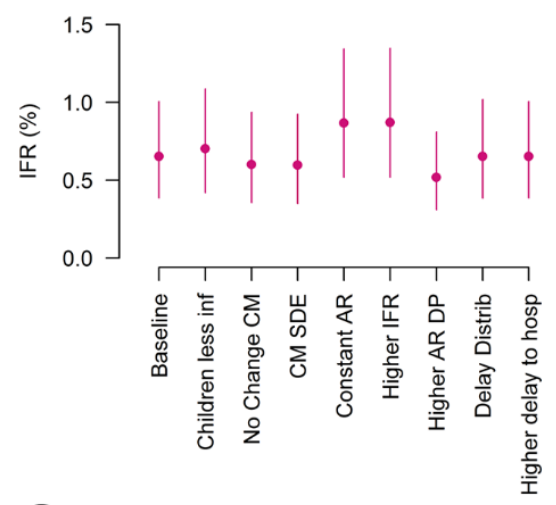

C

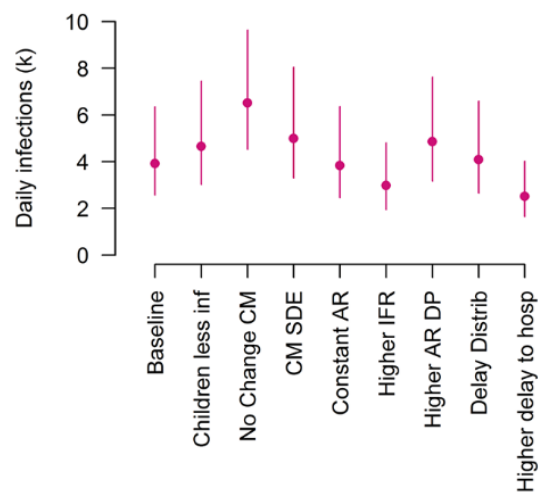

B

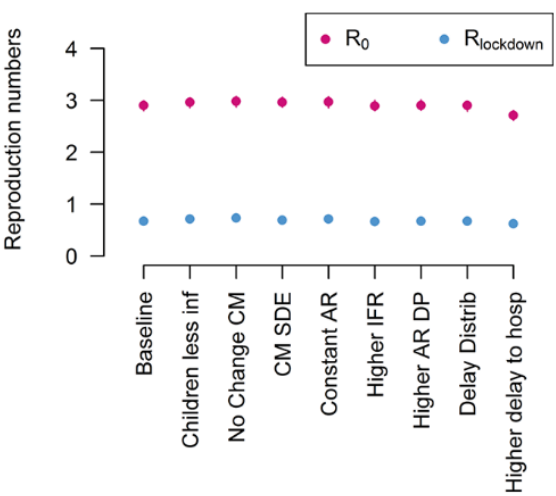

D

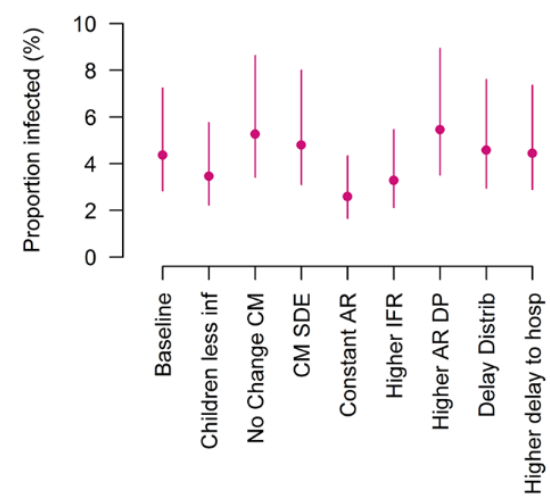

Fig. 4. Sensitivity analyses considering different modeling assumptions. (A) Infection fatality rate (\%). (B) Estimated reproduction numbers before $\left(R_{0}\right)$ and during lockdown $\left(R_{\text {lockdown }}\right)$. (C) Predicted daily new infections on 11 May. (D) Predicted proportion of the population infected by 11 May. The different scenarios correspond to: Children less inf. - Individuals <20ya are half as infectious as adults; No Change CM - the structure of the contact matrix is not modified by the lockdown; CM SDE - Contact matrix after lockdown with very high social distancing of the elderly; Constant AR Attack rates are constant across age groups; Higher IFR - French people $25 \%$ more likely to die than Diamond Princess passengers; Higher AR DP $25 \%$ of the infections were undetected on the Diamond Princess cruise ship; Delay Distrib - Single hospitalization to death delay distribution; Higher delay to hosp - 8 days on average between symptoms onset and hospitalization for patients who will require an ICU admission and 9 days on average between symptoms onset and hospitalization for the patients who will not. For estimates of IFR and reproduction numbers before and during lockdown, we report 95\% credible intervals. For estimates of daily new infections and proportion of the population infected by 11 May, we report the $95 \%$ uncertainty range stemming from the uncertainty in the probability of hospitalization given infection. 